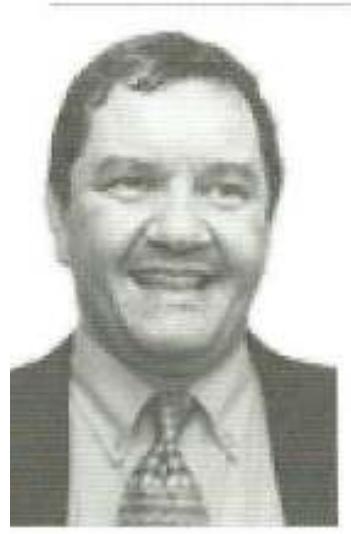

\title{
A reforma do ensino superior europeu a partir de Bolonha e sua influência no sistema brasileiro: $\mathrm{O}$ que o sistema privado tem a aprender? The reform of European higher education from Bologna and its influence on Brazilian system: What the private system has to learn?
}

\section{La reforma de la educación superior europea de Bolonia y su influencia en el sistema brasileño: Lo que el sistema privado tiene que aprender?}

Dimensōes históricas do Processo de Bolonha, suas principais mudanças no sistema europeu de educação superior e sua contextualização histórica. Análise da sua imfluência no projeto de restruturação do ensino superior brasileino, iniciado ainda no governo $\mathrm{FHC}$ e aprofundado com a implantaçâo do REUNI no governo Lula e seus efeitos práticos no sistema federal, no caso a UFABC e a UFBA, abordando em seguida as suas influencias no ensino superior privado.

\author{
Historical Dimensions of the \\ Bologna process your major changes in \\ the European system of higher education \\ and its historical context. Analyzing \\ its influence in the restructuring of \\ the Brazilian higher education project \\ also initiated the FHC government and \\ deepened with the implementation of \\ the MEETING Lula government and its \\ practical effects in the federal system. \\ where the UFABC and UFBa, focus. \\ ing then on their infuences in private \\ higher education.
}

Las dimensiones históricas del proceso de Bolonia tus cambios importantes en el sistema europeo de educación superior y su contexto histórico. El análisis de su influencia en la reestructuración del proyecto de educación superior de Brasil también inició el gobierno de FHC y profiandiza con la implementación del gobierno REUNIÓN Lula y sus efectos prácticos en el sistema federal, donde el UFABCy UFBa, centrándose luego en sus influencias en la educación superior privada.
Palavras-chave: Reforma do ensino superior, Bolonha, sistema privado.

\begin{abstract}
Autores:
Rainer Marinho da Costa

Graduado em História pela PUC SP (1988) e mestrado em História Social pela Universidade de São Paulo (1995). Especialista em Direito Educacional pelo CEU-SP. Especialista em Gestão Empresarial e com atuação em Gestão Escolar. Consultor Acadêmico na área de ensino superior
\end{abstract}

\section{Introdução}

Inicialmente temos que entender as dimensões do chamado Protocolo de Bolonha no seu processo histórico de implantação, o que para alguns autores europeus deveria se chamar Processo de Bolonha', verificando quais foram as principais mudanças no sistema europeu de educação superior, entendendo como e por que elas foram engendradas. A partir dessa perspectiva, analisar a sua influência no projeto de restruturação do ensino superior brasileiro, iniciado ainda no governo FHC e aprofundado com a implantação do REUNI no governo Lula e seus efeitos práticos no sistema federal, no caso a UFABC e a UFBA, abordando $\mathrm{cm}$ seguida as suas influências no ensino superior privado.

\section{Histórico do Processo de Bolonha}

O Processo de Bolonha é algo que vai além do docu-

'CROCHÉ, Sarah et CHARLIER Jean-Émile. "Le processus de Bologne el ses effers", numéro de "Education et sociétés", 2009/2 Disponivel em http-//www. sauvonsluniversile.com/spip.php?article 3621 acesso em 02/045/2012 mente em si assinado $\mathrm{cm} 1999$ na cidade que leva seu nome. A reforma do ensino superior europeu, iniciou-se na pratica um ano antes na reunião da Sorbonne em Paris, e previa sou implantação até 2010 , contudo não esgota nesse ano e vai alem do que foi escrito em Bolonha. Diversos documentos, produzidos nos encontros bianuais realisados pela UE, aprofundaram e detalharam o que lá foi escrito ${ }^{2}$.

É na Declaração ad Sorbonne, pela primeira yez formulada que a visão do EEES estruturado em torno de alguns graus de arquitetura comuns em dois ciclos principais objetivando melhorar a empregabilidade e a mobilidade dos estudantes europeus, o atratividade do sistema europeu de ensino superior. E por isso que, em retrospecto, a conferência a declaraçăo da Sorbonne pode ser considerado como o evento $\mathrm{e}$ documento de fundação do Processo de Bolonha ${ }^{3}$.

Temos que entender que a reforma engendrada pelo Processo de Bolonha é no fundo a colocação em pratica de uma reflexão feita pelos lideres da comunidade europeia de que ela deveria assumir um papel de relevância na educação mundial,

\footnotetext{
2NEVES, Clarissa Eckert Baeta. Reforma e desafios da educoçấo superior: o processo de Bolonha der anos depois. Disponivel em http:/revistappgsa.ifes, ufri. bripdfs/anolv1_artigo_clarissa-neves.pdf. Acesso em 30/03/2012

${ }^{3}$ CROCHÉ, Sarah et CHARL.IER Jean-Êmile, idem. Tradução livre: "C'est dans la déclaration de la Sorbonne ou est pour les premiene fois formulée la vision d'un EEES strucruré autour d'une architecture commune des diplómes en deux cycles principaux visant à amélioner la mobilité et l'employabilite des étudiants erropéens, l'atractivilé du système européen d'enseignement superrieur. C'est pourquol rétraspectivement la confénence er la déclaration de la Sorbonne pervent être envisagées comme l'événement et le docranent fondatezers du processus de Bologne
} 
tal qual vinha assumindo na economia e se tornar uma referência mundial, competindo com o sistema americano, recuperando assim o seu antigo status, perdido em parte no pós-guerra ${ }^{4}$.

O grande problema era que o modelo então existente era fruto de mais de 900 anos de historia. A realidade europeia era um sistema multifacetado e diverso, no qual era quase impossivel haver a integração de alunos e professores dos diversos paises membros. Integração era objetivada e almejada na própria existência da UE, para tanto se criaria a European Higher Education Area ${ }^{5}$.

Temos que compreender que o modelo de universidades existente até o fim da década de 90 na Europa era tributaria da do modelo engendrado por Humbolt na Alemanha é estava calcado no ensino e na pesquisa ${ }^{6}$, que veio a se tornar o modelo brasileiro. A partir dessa matriz, se criaram na Europa três modelos clássicos; $O$ francês, o alemão e o anglo-saxão, cada um com suas características próprias:

O processo de reestruturação das universidades em âmbito global vem revendo e criticando os três modelos clássicos europeus (tipologias ideais) do século XIX, principalmente a partir das últimas décadas do século $\mathrm{XX}$ :

a) o modelo francês, que se caracterizava pelo ensino público, leigo e padronizado, fortemente controlado pelo Estado e com ênfase na formaçåo de profissionais para o mercado de trabalho e ocupações nos quadros do próprio Estado:

b) o modelo alemão, e que a universidade caracterizava-se pela autonomia, com a responsabilidade do Estado pelo seu financiamento e a instituição buscava ser um centro intelectual de alta cultura e de qualidade assim como de realização da pesquisa e da formação da elite;

c) o modelo inglês, em que o ideal universitário partia do principio da formação nåo utilitária e da formação integral mediante um método praticamente individual, onde a pesquisa cientifica bem como a formação profissional eram relegadas a um segundo plano.

Em contrapartida aos modelos europeus, o sistema universitário estadunidense, que historicamente pautou-se por seu caráter imediatista e de utilidade para a nação, na metade do século $\mathrm{XX}$, começou a ser visto como um sistema competitivo, por caracterizar-se entre outros fatores, pela diversificação e hierarquização de IES que atendem a papéis diferenciados. Nesse sistema, estão presentes tanto universidades tradicionais, que realizam pesquisa e cnsino e recebem uma elite, quanto uma gama de IES que oferecem cursos curtos e profissionalizantes para uma massa de individuos ${ }^{7}$.

O pano de fundo, portanto da reforma é a busca de se repetir na educação o que vinha ocorrendo na economia: a unifi-

"LIMA Licinio C. I; AZEVEDOII , Mário Luiz Neves de; CATANIII, Afrânio Mendes. O processo de Bolonha, a avaliação da educaşão superior e algumas considerações sobre a Universidade Nova, Avaliação: Revista da Avaliação da Educaçâo Superior (Campinas) Avaliaçăo (Campinas) vol.13 no. I Sorocaba Mar. 2008. Disponivel http://dx.doi.org/10.1590/\$1414-40772008000100002, acesso $\mathrm{em} \mathrm{30/02/12}$

\section{${ }^{5}$ NEVES, Clarissa Eckert Bacta. Idem}

${ }^{6} \mathrm{CHIANG}$, Iris Kuang-Hsu: "Deux cents ans après la réforme d' Humboldt : Bologne Oì va l'enseignement supérieur eumpéen, Le processus de Bologne et ses effets", numéro de "Education et sociétés", 2009/2vendredi 26 mars 2010. Disponivel em http://www.sauvonsluniversite.com/spip.php?article3621, acesso em 1/04/2012

${ }^{7}$ FERREIRA, Suely. Reforma da educação superior no brasil e na Europa: em debate novos : Papéis sociais para as universidades. Disponivel http:/Www. anped_org.br/33encontro/app/webroot/files/file/Trabalhos\%20 em\%20PDF/GTI16003 -Int.pdf, acesso em 1/04/2012 cação do sistema de ensino superior num modelo que permitisse mobilidade $\mathrm{e}$ o aproveitamento do que era feito de um pais para outro. Criando um sistema que revisse as antigas tradições universitárias, transformando as instituições de ensino superior em centros, não só de excelência acadêmica, mas também de modelo de gestão, tal qual ocorria no EUA, fazendo com que a Europa voltasse ao cenário internacional educacional em condições de competir com as grandes universidades americanas ${ }^{8}$.

Tivemos, contudo de entender que a UE é no fundo uma organização federativa e como tal sempre tem de obter o apoio para suas resoluções nos parlamentos nacionais que a compõem? Num primeiro momento seria de se surpreender que modelos como Alemão e Francês, que foram referência durante séculos para outros paises, pudessem ser abaladas por tal reforma. Para surpresa, esses paises adotaram as propostas, pois no fundo perceberam a necessidade de aggiornamento o seu modelo de ensino. Cabe ressaltar, contudo, que isso não é um consenso, muitos alunos e professores reclamam que o modelo fez cair a qualidade de ensino, sobretudo pela redução de anos de estudos nos ciclos iniciais.

Segundo autores franceses, o que define o Processo de Bolonha é:

Contudo colocam as principais criticas ao modelo:

Ao mesmo tempo, ele foi acusado de todos os males, ele é acusado de ser o vetor da mercantilização do ensino superior, para servir apenas os ideais de competição entre as regiôes, contribuindo para a exploração do pais Sul,(... "* os procedimentos de controle e garantia de qualidade estão longe de niveis padronizados e generalizada, de estudo não são harmonizadas, os ECTS nâo se aplica em todos os lugares. ${ }^{11}$

O objetivo não é promover igualdade e sim equivalência entre os diversos sistemas nacionais. Buscando integrar os sistemas universitários nacionais, de forma a equiparar graus, diplomas, títulos universitários, currículos acadêmicos e adotar programas de formação contínua que tenham equivalência nos membros da União Europeia ${ }^{11}$. O processo em si previa segundo NEVES(2011) o seguinte:

- adoção de um sistema de graus facilmente compreensiveis e comparáveis:

- adoção de um sistema baseado em dois ciclos de ensino, o Bachelor e o Master;

- estabelecimento de um sistema de acumulaçăo e de transferềncia de créditos (tal como o European Credit Transfer System (ECTS), já em uso nos programas Sócrates e Erasmus);

- promoção da mobil idade de estudantes, docentes, investigadores e outros trabalhadores, removendo os obstáculos administrativos

${ }^{8}$ LIMA Licinio C. I; AZEVEDOII , Mário Luiz Neves de; CATANIII, Afrânio Mendes. Idem.

"MARTINS, Leila Chalub e NASCIMENTO, Elimar Pinhero do . O Processo de Bolonha no Ensino Superior da América, Latina: o caso brasileiro IN PENAVEGA, Alfredo (Coord.) O Processo de Bolonha no Ensino Superior da América Latina OBSERVATORIO INTERNACIONAL DE REFORMAS DA UNIVERSI$D A D E$ Disponivelhttp://www.gulbenkian.pt/media/files/agenda/eventos 2009/ Futuro $\% 20 \mathrm{de} \% 20$ Bolonha/TRADUCTION_PROCESSO_BOLONHA_FINALAL 4 . pdf acesso em 30/03/12

${ }^{10} \mathrm{CROCHÉ}$, Sarah et CHARLIER Jean-Émile, ibdem. Tradução livre"ll est présenté comme la réforme qui jette les universités dans le troisième millénaire, qui est appelée à révolutionner les pratiques pódagogiques, à ouvrir l'universíté à tous les publics et à toutes les formes de développement des compétences professionnelles, qui va faire de l'Europe un phare pour le reste du monde"

"LIMA Licínio C. 1; AZEVEDOII, Mário Luiz Neves de; CATANII, Afrânio Mendes. Ibdem. 
e legais ao reconhecimento de diplomas;

- promoção da cooperação europeia na avaliação da qualidade da educaçẫo superior.

- promoção do Espaço Europeu de Educação Superior..$^{12}$

Pelo quadro abaixo, verificamos o andamento e quais mudanças foram realizadas no sistema de ensino superior nos últimos anos na Europa.

\section{Cronologia do Processo de Bolonha}

\begin{tabular}{|c|c|}
\hline $\begin{array}{c}1998 \\
\text { Declaração } \\
\text { de Sorbone }\end{array}$ & $\begin{array}{l}\text { Mobaidade de estruturas professcres } \\
\text { Implementaçåo de um sistema comum de dois ciclos } \\
\text { Promoçäo da Europa do conhecimento }\end{array}$ \\
\hline $\begin{array}{c}1999 \\
\text { Declaração } \\
\text { de Bolonha }\end{array}$ & $\begin{array}{l}\text { Impientação do sistema de créditos (ECTS) } \\
\text { Titúas facilmente legiveis e comparáveis. } \\
\text { Dimensäo europeia da educaçăo superior e formento } \\
\text { à mobilidade. } \\
\text { Cooperaçäo europela para a garantia da qualidade }\end{array}$ \\
\hline $\begin{array}{l}2001 \\
\text { Declaraçăo } \\
\text { de Praga }\end{array}$ & $\begin{array}{l}\text { Aprendizagem ao longo da vida. } \\
\text { Inclusão da dimensão social. } \\
\text { Envolvimento de Instituiçōes de educaçăo superior e } \\
\text { de estudantes. } \\
\text { Promoçäo do Espaço Europeu de Educaçāo Superior. }\end{array}$ \\
\hline $\begin{array}{l}2003 \\
\text { Comunicado } \\
\text { de Berlim }\end{array}$ & $\begin{array}{l}\text { Vinculos mais estreitos entre investigação e educação. } \\
\text { Inclusăo do doutorado oom } 3^{\circ} \text { ciclo. } \\
\text { Marco europeu de qualificaçöes (EQF). } \\
\text { Reconhecimento das titulaçōes a dos periodos } \\
\text { de estudo (Suplemento ao Diploma). } \\
\text { Garantia de qualidade no nivel institucional, nacional e europeu. }\end{array}$ \\
\hline $\begin{array}{l}2005 \\
\text { Comunicado } \\
\text { de Bergen }\end{array}$ & $\begin{array}{l}\text { Consclidaçāo da dimensāo social. } \\
\text { Marcos nacionais de qualificaçōes. } \\
\text { Concessāo e reconhecimento de titulos conjuntos. } \\
\text { Parămetros e ciretrizes para a garantia de qualidade. }\end{array}$ \\
\hline $\begin{array}{l}2007 \\
\text { Comunicado } \\
\text { de Londres }\end{array}$ & $\begin{array}{l}\text { Compromisso de elaboração de planos de açāo } \\
\text { nacionais com um controle eletivo sobre a dimensäo social. } \\
\text { Estratégia para melhorar a dimensão global do } \\
\text { Processo de Bolonha. } \\
\text { Criação de um Registro Europeu de Qualidade. }\end{array}$ \\
\hline
\end{tabular}

\begin{tabular}{|c|c|}
\hline \multirow{7}{*}{$\begin{array}{l}2009 \\
\text { Comunicado } \\
\text { de Lewven }\end{array}$} & Meta de $20 \%$ até 2020 para a mobisidade estudanti. \\
\hline & Quadro de qualificapōes nacionais até 2012. \\
\hline & Metas nacionais para a dimensão social até 2020. \\
\hline & $\begin{array}{l}\text { Educaçäo continuada como responsabilidade } \\
\text { pública com base em parcerias. }\end{array}$ \\
\hline & Qualidade como foco importante para Área de \\
\hline & Educaçāo Supericr Europeia. \\
\hline & $\begin{array}{l}\text { Ampliar o diälogo de politicas globais por meio } \\
\text { do Fónum de Bolonha. }\end{array}$ \\
\hline
\end{tabular}

Fonte:Eurydice/EACEA 2010

\footnotetext{
${ }^{12}$ NEVES, Clarissa Eckert Bacta. Ibdem
}

Numa analise detalhada deste quadro percebemos que a ideia principal foi criar um sistema unificado que possibilitasse diminuir as diferenças existentes entre os sistemas nacionais. Na prática houve uma reformulação das durações dos diversos curso oferecidos, por exemplo as licenciaturas na França que tinham uma duração de cínco anos, pelo novo sistema de ciclos caíram para 3 anos, o que repercutiu muito mal na sociedade francesa que valoriza a formação de professores. Dessa forma, o modelo de dois ciclos tem a seguinte caracteristica: ciclo inicial de formação no mínimo de três anos, segundo ciclo de pós-graduação stricto sensu de dois anos para o mestrado e três anos para o doutorado.

Um aspecto que, contudo nâo aparece claramente, nos documentos acima é a busca de uma nova forma de gestão acadêmica do sistema, buscando uma eficiência mais empresarial o que antes estava não era objetivada.

No fundo a mudança objetiva uma restruturação para diminuição do tempo gasto na formação superior para garantir uma competividade com o sistema americano, que pela sua formatação coloca mais rápido o jovem no mercado, e investe na pós-graduação para formação de ponta do aluno. O Processo de Bologna tem este objetivo que somado aos das declarą̧ões dos anos seguintes amplia o seu escopo.

\section{Cabe aqui, portanto uma pergunta:}

O Protocolo de Bolonha tem um Plano Curricular Inovador?

Em pesquisa de base de dados francesas percebemos que existem severas criticas ao modelo, dizendo na verdade que o modelo proposto, pelo menos no aspecto de arquitetura curricular, nada mais que uma cópia do modelo norte americano, tanto na divisão de ciclos como na duração. Cabe ressaltar a eficiência desse modelo, pois de um lado permite uma profissionalização rápida, com a curta duração da pós-graduação, bem como o caráter de formação geral no primeiro ciclo, além do fato de ter uma gestão acadêmica empresarial ${ }^{13}$.

Percebemos por essa leitura que na verdade o Processo de Bolonha não é uma verdadeira Inovação, mas sim uma a adaptação a uma realidade para atender aos interesses de tornar a Europa numa referência mundial de formação de nivel superior.

O processo de Bolonha e a criação de um espaço curopeu de ensino superior e de pesquisa visa tornar a Europa em uma "a economia do conhecimento mais competitiva do mundo", meta definida pelo Conselho Europeu de Lisboa $\mathrm{cm} 2000$. Embora scja evidente que as reformas de Bolonha são parte de uma perspectiva cconômica claramente posta (Kwiek 2003, Kellermann 2007). o objetivo inegável é criar uma dimensäo espacial europeia de ensino superior e pesquisa. Um progresso considerável foi feito com o LMD (Licence-Master-Doutoramento), a aplicação da transferência de créditos Europeu e diferentes padrōes de mobilidade na maioria dos países curopeus. No entanto, as reformas de Bolonha săo geralmente somente percebidas como um processo de harmonização compatibilidade c comparabilidade (Floud 2006, 13; Reichert \& Tauch, 2005, 4; Wächter 2004).

Coordenaçăo da investigação ou produçẫo de recursos na escala europeia significam portanto a existência de uma dimensão ou uma investigação do espaço europeu? Vejamos como os EUA vê o processo de Bolonha. Floud, em um artigo publicado na Mudança (julho-agosto 2006), considerando as reformas de Bolonha como uma transferência de um modelo tradicional europeu no modelo anglo-americano. "Portanto, não é surpreendente que o processo de Bolonha reproduz o modelo EUA (ou

13" Le processus de Bologne et ses effets", numero de "Education et sociétés", 2009/2vendredi 26 mars 2010. Disponivel em http:/www.sauvonsluniversite. com/spip.php?article3621, acesso em 1/04/2012 
britânico-irlandês). A distribuição dos três ciclos (licenciatura. mestrado e doutoramento) foi o objetivo de reproduzir "(11). As reformas de Bolonha são descritos no final do artigo como "a transiçŭo da Ruritãnia para Chicago" (12).

Um marco nesse processo foi em 2003 a implantação do sistema europeu de créditos (ECTS-European Credit Transfer and Accumulation System), tendo regras claras de contagem, além de oferecer aos estudantes o Suplemento ao Diploma, "um documento escrito numa língua estrangeira de grande circulaçăo onde se descreve o programa de estudos e, entre outros elementos, se certificam as chamadas "competências transversais" de cada aluno."15

\section{Análise das influências do Processo de Bolonha no ensino superior público brasileiro}

A historia do ensino superior brasileiro não é muito longínquoa temos em torno de 200 anos. Isso sem contar o periodo dos seminários jesuiticos que existiriam no periodo colonial que fizeram a função de ensino superior.

O modelo que imperou, sobretudo no ensino publica superior foi o europeu de origem francesa e alemão, contudo a partir do final dos anos 60 o modelo americano entre em voga como algo ser copiado( a criação da UNB). Vimos seu reflexos pela implementação da Lei 5564/68 de Reforma do Ensino Superior, e pela LDB Lei $5692 / 71$

O sistema sofre uma nova mudança em 1996 com a nova LDB que teve o projeto original elaborado pelo antropólogo Darcy Ribeiro, com uma ampla influencia do modelo americano, que sobrevive, com várias alterações na versão aprovada.

Em função disso, inicia-se no governo $\mathrm{FHC}$ a reestruturação do sistema de ensino superior, tanto publico como particular. A implantação das diretrizes curriculares que atingem os dois segmentos veio trazer coisas interessantes, que de alguma forma vão ao encontro do que o Protocolo de Bolonha coloca, apesar de que num primeiro momento apareça o contrário.

Saimos dos chamados currículos minimos nacionais, que homogeneizava o sistema possibilitando uma navegabilidade/ mobilidade quase plena entre os cursos das diversas IES para um currículo que possibilitava uma liberdade de personalização de cursos muito grande, fazendo com que essa possiblidade se

\footnotetext{
${ }^{14} \mathrm{CHIANG}$, Iris Kuang-Hsu, idem:Traducho livre: "Le processus de Bologne ainsi que la mise en place d'un espace européen de l'enseignement supérieur et de la recherche visent à faire de l'Europe "Y'économie de la connaissance la plus compétitive au monde", objectif défini lors du Conseil européen de Lisbonne en 2000. Même s'il est clair que les réformes de Bologne s'inserivent dans une perspective nettement économique (Kwiek 2003, Kellermann 2007), l'objectif de créer une dimension et un cspace européens dans l'enseignement supérieur et la recherche est indéniable. Des progrés considérables ont été réalisés avec la réforme LMD (Licence-Master-Doctorat), l'application du système europécn de transfert de crédits et différents schémas de mobilité dans la plupart des pays européens. Pourtant, les réformes de Bologne sont en général perçues comme un processus d'harmonisation, de compatibilité et de comparabilité (Floud 2006, 13 : Reichert \& Tauch 2005, 4 ; Wächter 2004)." (...)

(...) ${ }^{4} \mathrm{La}$ coordination des recherches ou la production de ressources à l'échelle européenne signifient-elles pour autant l'existence d'une dimension ou d'un espace curopéens de la recherche? Intéressons-nous à la façon dont les États-Unis voient le processus de Bologne. Floud, dans un article publié dans Change (juillet-aoûtt 2006), envisage les réformes de Bologne comme le passage d'un modèle européen traditionnel au modèle anglo-américain. "Il n'est donc pas surprenant que le processus de Bologne reproduise le système américain (ou britannique-itlandais). La répartition des études en trois cycles (licence-master-doctorat) était l'objectif à reproduire" (11). Les réformes de Bologne sont décrites en fin d'article comme "la transition de Ruritania vers Chicago" (12

${ }^{15}$ LIMA Licinio C. 1; AZEVEDOII, Mário Luiz Neves de; CATANII, Afránio
} Mendes. Ibdem reduzisse. Contudo as diretrizes trouxeram também uma estruturação dos currículos em quatro niveis; Formaçăo básica, formação instrumental, formação profissional e formação complementar. Contudo como indica Marinho $(2011)^{16}$, a maioria das IESP não souberam aproveitar as oportunidade, de criarem algo diferente, tal qual Bolonha indicava o caminho

Com a implantação do Programa de Reestruturação e Expansão das Universidades Federais brasileiras (REUNI) pela lei 6.096 de 24 de Abril de 2007, objetivava-se possibilitar as universidades federais ampliar as condiçōes de acesso e permanência dos estudantes na educação superior levando algumas IES federais a inovarem por meios de seus PDI as formas com que ofertavam seus cursos. No fundo, o objetivo era ampliação de vagas inicias e diminuição da evasão nos cursos presenciais de graduação. Das 53 universidades que aderiram ao Reuni somente 26 fizeram grandes alterações acadêmicas; as outras buscaram, sobretudo os recursos financeiros disponiveis para reforma e investimento em infraestrutura deixando de lado as questőes pedagógicas. ${ }^{17}$

Segue a integra de um quadro publicado na revista Ensino Superior que apresenta as principais alterações acadêmicas nas federais, frutos do projeto;

Inovações acadêmicas por universidade

TipoUniversidadelnovaçâo Acadêmica

1- Formação em ciclos: Geral, Intermediário, Profissional, ou de Pós-Graduação

a) Fundação Universidade Federal do TocantinsFormaçâo em 3 ciclos:

i. Geral, Profissional e de Pós-Graduação;

Campi de Araguaina, Palmas e Gurupi: scis áreas de conhecimento: Ciências Naturais, Artes e Filosofia, Ciências da Saúde, Ciências e Tecnologia, Ciências Agrárias e Ambientais e Gestão (cowm proposta de cursos tecnólogos). Implantaçāo progressiva de outros primeiros ciclos nas áreas de conhecimento já existentes na UFT

b) Universidade Federal de Minas Gerais

i. Curriculos em 3 Núcleos: (formação específica, complementar $\mathrm{e}$ atividades livres).

c) Universidade Federal de Alagoas

i. Campus Arapiraca: desde a Expansão Fase 1: 2 campi no interior com pólos circundantes; Novo modelo pedagógico: Eixos (saúde, educaçåa, agrárias, gestão, tecnologia, etc) e Troncos (ciclos: inicial, intermediário e profissionalizante). Campus Deimiro Gouveia

d) Fundação Universidade Federal do Maranhẫo

2 - Formação básica comum para todos os cursos de graduaçăo: gcral (ciclo básico) ou por grandes áreas

a)Fundação Universidade Federal da Grande Dourados

i. Ciclo de formação geral para todos os cursos; Reserva de vagas para $25 \%$ dos egressos da escola pública em todos os cursos.

${ }^{16}$ MARINHO, Rainer, A implantaçăo de curso de graduação na forma modular flexivel num Centro Universitário, disponivel em http://mconsultoria.wordpress. com/2010/06/27/a-implantacao-de-curso-de-graduacao-na-forma-modular-flexivel-num-centro-universitario/ acesso em 31/03/2012

${ }^{17}$ REVISTA ENSINO SUPERIOR, Currículos em Mudança, disponivel em http://revistaensinosuperior.uol.com.brtextos.asp?codigo $=12393$ 
a criação e ciclo básicos, o que não é uma inovação (veremos isso mais adiante). Somente o quarto e quinto item e que apresentam as duas grandes inovações são os itinerários distintos e os chamados Bacharelados Gerais, Interdisciplinares, fruto do movimento da Universidade Nova.

O modelo da UNIVERSIDADE NOVA que propōem uma estrutura acadêmica da educação superior que teria três ciclos: Bacharelado Interdisciplinar $\left(1^{\circ} \mathrm{Ciclo}\right)$; Formação Profissional $\left(2^{\circ}\right.$ Ciclo); Pós-Graduação ( $3^{\circ}$ Ciclo). De acordo com o Documento Preliminar para Consulta Pública da Universidade Federal da Bahia (UFBA), as seguintes instituiçōes implantaram o modelo Universidade de Brasilia (UnB), Universidade Federal do Piauí (UFPI) e Universidade Federal do ABC (UFABC).

Em uma reportagem da Revista Ensino Superior se abordou essa reforma mostrando o potencial da mesma, basta vemos o título da matéria:

Opção pela mudança: Universidades Federais discutem o projeto Universidade Nova, que pode mudar completamente o perfil curricular do ensino superior no Brasil. ${ }^{19}$

Para alguns autores esse modelo ajudaria a combater profissionalização precoce bem como a evasão, no parágrafo abaixo temos as diferenças dos modelos de Bolonha e da Universidade Nova adota pelas UFBA E UFABC:

Para Almeida Filho (2007), a introduçẫo de cursos de ensino superior de três anos, com enfoque generalista, pode combater a evasāo, ampliar a relaçăo alunóp professor, bem como, modernizar e compatibilizar o sistema de educação superior brasileiro com os sistemas norte-americano e europeu (2007). Porém, ao comparar com os ciclos introduzidos pelo Processo de Bolonha -3 anos (gractuação) +2 anos (mestrado) +3 anos (doutorado), as cuusos. resse caso, ficaram mais curtos, expecializados e com opcâo mais rápida de saida para o mercado de trabalho, sem preocupacão com a escolha precoce do curso superior: Os ciclos do $\mathrm{BI}$ parecem fazer um movimento contrário, ficando mais genéricos e com uma "formaçäo geral humanistica" : oferecem um diploma de hachavel has áreas de artes, humanidades, sanide ciências e tecnologias: $e$ podem aumentar o periado de permanéncia para que as desejam ter de fato uma formação profissional. O Bl constitui-se no primeiro ciclo de formação. No segundo ciclo, ocorreria ả formação superior nas áreas de docência para licenciaturas, carreiras especificas e mestrado e, no terceiro ciclo, ocorreria o curso de doutorado. $\mathrm{O}$ projeto de Lei 7.200/2006 do governo para reforma da educaçāo superior, em tramitação no Congresso Nacional, reafirma a proposta de reorganizar os cursos de graduaçâo, incluindo um periodo de formação geral em quaisquer campos do saber com duração minima de quatro semestres." 20 (grifo nasso)

Esse modelo mesmo se propondo a superar o modelo americano e o modelo de Bolonha traz sim as contribuiçôes dos dois modelos. Cabe ressaltar que no caso de utilização de três ciclos ao em vez de dois proposto por Bolonha, vem atender uma realidade brasileira que não a aceitaria facilmente um graduado em generalidades, havendo a necessidade de uma continuação na graduação para obtenção, seja do bacharelado ou da licenciatura no segundo ciclo profissional, o que não ocorre pela proposta de Bolonha que coloca somente dois ciclos um de formação outro de profissionalização.

${ }^{19}$ MELLO, Alex Fiúza da; ALMEIDA FILHO, Naomar de: JANINE RIBEIRO, Renato. POR UMA UNIVERSIDADE SOCIALMENTE RELEVANTE, disponivel em http://portal.mec.gov.br/dmdocuments/cne_alexfiuza.pdf acesso em 31/03/2012.

${ }^{20}$ LIMA Licinio C. 1; AZEVEDOI, Mário Luiz Neves de; CATANIII, Afrânio Mendes. Ibdem
O primeiro ciclo, chamado de B.I.- Bacharelado Interdisciplinar seria um nivelamento em um ciclo básico de duração de 2 anos, mais estendido, que apesar de possuir uma terminalidade necessita do segundo ciclo para uma profissionalização como veremos diante.

A chamada Universidade Nova vai operar um completa mudança nas matrizes curriculares das universidades públicas brasileira: que, segundo um de seus idealizadores, Naomar de Almeida Filho ${ }^{21}$, antigo Reitor da UFBA, pretende superar a dicotomia entre o Modelo Norte-Americano (de origem flexneriana) e o Modelo Europeu, por isso ele diz "Nem Harvard Nem Bolonha". ${ }^{22}$ A proposta se baseia na adoção de um sistema de três ciclos de educação superior:

\footnotetext{
--Primeiro Ciclo: Bacharelado Interdisciplinar (BI), propiciando formação universitária geral, como pré-requisito para progressão aos ciclos seguintes;
}

- Segundo Ciclo: Formaçāo profissional em licenciatums ou carreiras especificas:

- Terceiro Ciclo: Formação acadêmica cientifica, artística c profissional da pós-graduação. ${ }^{23 .}$

Seguindo o modelo abaixo:

Arquitetura curricular da Universidade Nova

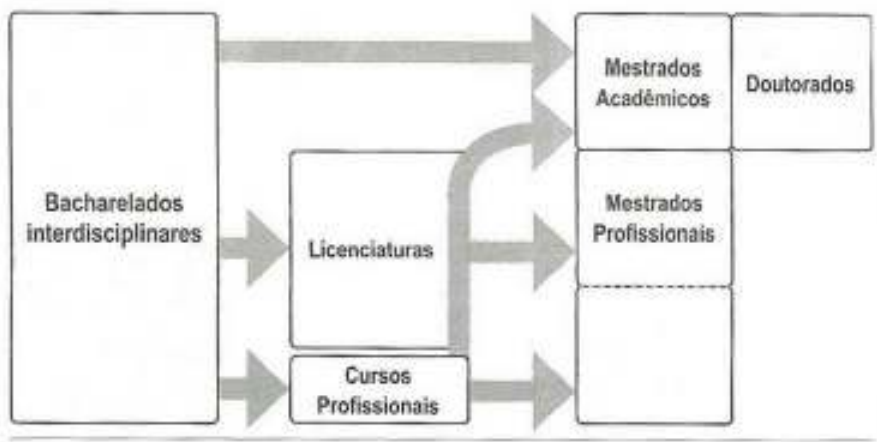

Fonte: UFBA,2007, p. 9

Que funciona da seguinte forma:

"a) formação profissional de graduação;

b) formação científica ou artística de pós-graduaçâo. Terá duração de 6 semestres (ou ainda, 9 trimestres), com uma carga horária total minima de 2.412 horas.

A Carga Curricular do Bacharelado Interdisciplinar baseia-se no conccito de Blocos Curriculares, definidos como conjunto de módulos (cursos, disciplinas, atividades, programas, trabathos orientados) cobertos pelos alunos durante o semestre ot quadrimestre letivo. Cada módulo equivale a quatro (4) horas semana de atividade em sala de aula/ laboratório/ observatório. $\mathrm{O}$ Bl compreende um mínimo de 24 e um máximo de 32 componentes curriculares [...]. ${ }^{24 .}$

${ }^{21}$ LIMA Licinio C. 1; AZEVEDOI, Mário Luiz. Neves de; CATANIII, Afrănio Mendes. Ibdem

${ }^{22}$ UFBA, Universidade Nova: Plano de Expansão e Restruturação da Arquítetura Curricular na Universidade Federal da Bahia. Documento Preliminar. Campinas, Mimeo

${ }^{23}$ UFBA, Universidade Nova: Plano de Expansão e Reestruturação da Arquitetura Curricular na Universidade Federal da Bahia. Documento Preliminar. Campinas, Mimeo, 2007, p. 9-10 
O modelo usado na UFABC tem suas particularidades, mesmo tendo a mesma inspiração da UFBA, contudo fica evidente seu maior ao Processo de Bolonha, do que a proposta da Universidade Nova, pelo menos no seu discurso pretende superar. A proposta é adotar os bacharelados interdisciplinares.

A UFABC tem seis eixos interdisciplinares, os Bacharelados interdisciplinares ocorrem em quadrimestres, onde os alunos matriculados estudam 3 quadrimestres ( 3 periodos de 4 meses) ao ano, o que leva aos alunos cursarem $50 \%$ mais disciplinas em comparação ao formato semestral ( 2 períodos de 6 meses) .

O ciclo básico, o aluno tem opções: uma focada no mercado de trabalho com o diploma de bacharel em Ciência e Tecnologia, outra continuar na universidade e cursar mais um ou dois anos em bacharelados ou licenciaturas específicos, além de oito diversas modalidades de engenharia. Há também a possibilidade de um mestrado ou de transferência para cursos de formação superior em outras IESs.

Segundo o site da IES o "egresso dos bacharelados interdisciplinares da universidade pode ingressar $\mathrm{em}$ uma das 21 opçôes de cursos de graduação conforme sua formação básica, divididos em bacharelados e licenciaturas"

Devemos contudo lembrar que a grande proposta de Bolonha é a integração dos sistemas nacionais para possibilitar uma mobilidade de alunos entre IES dos vários paises por isso foram criados os dois ciclos e a possibilidade de equivalência: de créditos na European Higher Education Area. No caso de uma universidade o que houve a criação da possibilidade de mobilidade entre os cursos propostos e não uma integração do sistema universitário federal e também a ideia de se ter um ciclo separado de profissionalização que ocorre após o inicio do curso. Sendo isto interrogação uma interrogação quanto a sua pertinência tenso em vista que vários autores brasileiros ressaltam que o público jovem quer uma profissionalização logo no inicio do curso.

O Modelo da Universidade Nova, contudo sofre diversas criticas no seio da comunidade acadêmica das IES envolvidas ${ }^{25}$. pois essa arquitetura curricular permite uma maximização de recursos humano e físico.

Iremos aqui reproduzir textualmente as apresentadas pelos três grupos formadores de opinião que estão envolvidos no processo: professores, funcionários e alunos.

\begin{abstract}
ANDES:
O Programa REUNI é uma ação de coerção, que precisa ser entendida na correta dimensāo da ameaça que configura, pois pode resultar no redesenho completo da funçào das universidades pủblicas federais. Acenando com verbas que nāo ultrapassam $10 \%$ a $20 \%$ do que atualmente é destinado às IFES, esse Programa pretende induzir os órgãos superiores das instituiçōes a se comprometerem com expansōes da ordem de I00\%, no número de ingressantes, e de $200 \%$, no das matriculas. Tais números estão escondidos por trás da 'meta global', anunciada logo no $\$ 1^{\prime \prime}$ do art. $1^{\circ}$ do Decreto $n^{\circ} 6.096$, de 24 de abril de 2007 , que institui o REUNI: elevar, num prazo de 5 anos, a taxa média de conclusťo dos cursos de graduação presenciais para $90 \%$ e da relação de alunos de graduação em cursos presenciais por professor para 18.
\end{abstract}

\footnotetext{
${ }^{24}$ MARTINS, Leila Chalub e NASCIMENTO, Elimar Pinheiro do, fdem

25 Apud MARTINS , Leila Chalub e NASCIMENTO, Elimar Pinheiro do .O Processo de Bolonba no Ensino Superior da América, Latina: o caso brasileiro IN PENA-VEGA,Alfredo (Coord.) O Processo de Bolonha no Ensino Superior da América Latina, OBSERVATORIO INTERNACIONAL DE REFORMAS DA UNIVERSIDADE Disponivethup://www.gulbenkian_pt/media/files/agenda/ eventos_2009/Futuro\%20de\%20Bolonha/TRADUCTION_PROCESSO BOLONHA FINAL -4.pdf acesso em 30/03/12
}

Queremos a expansâo das universidades públicas, sim, mas uma expansão que prime pela melhoria da qualidade do ensino, da pesquisa e da extensão, e não uma expansăo apenas para melhorar estatisticas. E essa expansão que defendemos precisa de recursos para a melhoria das estruturas dos campi, contrataçào de professores e valorizaçăo dos já existentes", defende Agostinho Beghelli, $2^{\circ}$ vice-presidente do ANDES-SN (ANDES, 2007, noticias). ${ }^{26}$

\section{SPBC}

Os Secretários Regionais da SBPC das regiōes Sul e Sudeste, Maria Alice Lahorgue e Maira Baumgarten (RS). Marcos Cesar Danhoni (PR), Maria Suely Soares (seccional Curitiba), Suzana Salem Vasconcelos e Joăo Emesto Carvalho (SP), reunidos em Porto Alegre nos dias 29 e 30 de outubro de 2007 , discutiram as linhas gerais do Programa de Apoio a Planos de Reestruturaçâo das Instituiçôes Federais de Ensino Superior e manifestam seu estranhamento e preocupação diante da constataçăo de que tal programa representa a prática de politicas contidas na proposta de Reforma do Ensino Superior do Governo Federal, as quais ferem frontalmente a concepçló e a autonomia da Universidade Brasileira $24 \mathrm{e}$ apresentam sérias implicaçōes futuras em relação à qualidade do ensino, da pesquisa e da extensão nestas instituiçōes ${ }^{27}$

\section{Estudantes}

Os estudantes, por sua vez, por meio das entidades estudantis, criaram o Livro Cinza do REUNI - Dossiê-Denúncia das Consequeências do REUNI, organizado pelo Diretório Académico de Fonoaudiologia da UFBA a partir de relatos vindos de diversas universidades do Pais e propōem a revogação do REUNI.

São nove depoimentos apresentados por representantes estudantis, das Universidades, em que se lê:

No dia em que o REUNI foi aprovado, nos deparamos com cerca de 300 policiais "tomando conta" da reuniăo do Conselho Superior.

\section{A truculência policial se explica:}

O plano de expansão aprovado em nossa universidade prevê um aumento do número de matriculas, passando dos atuais 10.500 a 19.000 até o final de 2012 , ou seja, cerca de $80 \%$ a mais de estudantes, Mas a verba destinada a essa expansão (48.660 miThôes) representa apenas $20 \%$ do orçamento anterior ao REUNI" (centro acadêmico da UFJF),

Em um recente artigo, o Prof. Naomar fez um balanço da iniciativa da Universidade Nova:

Em 2010, a Universidade Estadual Paulista (Unesp) abriu, no campus de Barra Funda, o bacharelado em ciências exatas, com um primeiro ciclo de trếs anos e quatro opçôes de segundo ciclo. Nesse mesmo ano, a Universidade Estadual de Campinas (Unicamp) iniciou o Programa de Formaçào Interdisciplinar Superior (Profis), curso sequencial de dois anos, primeiro ciclo para opçỏes de formaçāo profissional destinado aos melhores alunos do ensino público.

\footnotetext{
${ }^{26}$ Apud MARTINS Leila Chalub e NASCIMENTO, Elimar Pinheiro do. O Processo de Bolonha no Ensino Superior da Aménica, Latina: o caso brasileirc IN PENA-VEGA,Alfredo (Coord) O Processo de Bolonha no Ensino Superior da América Latina, OBSERVATÓRIO INTERNACIONAL DE REFORMAS DA UNIVERSIDADE Disponivelhtip://www.gulbenkian_pt/media/files/agenda/ eventos 2009/Futuro $\% 20 \mathrm{de} \% 20$ Bolonha/TRADUCTION_PROCESSO_BOLONHA_FINAL-4.pdf acesso $\mathrm{cm} 30 / 03 / 12$

${ }^{27}$ Idem

${ }^{28}$ Ibdem
} 
Eis um balanço da situação atual: em 13 universidades brasileiras, iniciam-se experiências com o regime de ciclos, $\mathrm{com} 16$ bacharelados interdisciplinares. Em 2011 , serão ofertadas 7.464 vagas, totalizando mais de 11 mil matriculas em 26 cursos de primeiro ciclo.

O marco conceitual desse projeto repousa sobre três cixos: em primeiro lugar, epistemologias não-cartesianas demandam e valorizam a inter/ transdisciplinaridade, o que permite integrar saberes das artes e das humanidades ao universo da pesquisa e da formaçăo. Em segundo lugar, teorias criticas da sociedade promovem a etnodiversidade nos processos educacionais. Em tercciro lugar, uma pedagogia emancipatória permite formar sujeitos com autonomia e inventividade, portanto mais bem preparados para cumprir a missũo (trans)formadora da instituição universitária. As categorias de etnodiversidade, interdisciplinaridade e autonomia constituem referências para pensar e agir frente a problemas complexos, estruturantes e emergentes, na contemporaneidade. ${ }^{29}$

Aqui vale uma ressalva histórica. Nos anos setenta, a PUC SP programou no o chamado Ciclo Básico( 1971 a 1986), sobre inspiração de vários educadores que participaram de seu projeto e implantação, que buscava uma proposta interdisciplinar e de formação humanistica, na qual todos os alunos ao ingressarem na faculdade em agrupados não por suas escolhas de cursos mas em classes com alunos de diversos cursos diferentes para cursarem 5 disciplinas de formação humanística durante os dois primeiros semestres, tendo somente duas disciplinas especificas dos cursos escolhidos. ${ }^{30} \mathrm{O}$ que hoje volta à baila com o Protocolo de Bolonha e a Universidade Nova.

Inclusive devemos entender que se a inovação for simplesmente a implantação de ciclos, estaremos caindo numa falácia histórica, pois como diz um criadores da Universidade Nova, o Prof. Naomar Almeida Filho:

O regime de ciclos não é novidade, nem no mundo nem no Brasil. No século XIX, Daniel Gilman implantou-o na Universidade Johns Hopkins e Abraham Flexner consolidou-o em todo o sistema universitário dos EUA, no começo do século XX. No Brasil, Anisio Teixeira o adaptou ao contexto nacional na heróica Universidade do Distrito Federal (UDF) em 1934 e depois, com Darci Ribeiro, recriou-o na Universidade de Brasilia (UnB) de 1961. Hoje, com o avanço do processo de Bolonha, trata-se da arquitetura curricular predominante nos paises europeus. ${ }^{31}$

Nesse ponto fica um questionamento: a Universidade Nova trouxe um ciclo básico inicial, chamado de B.1., agora em 3 anos não profissionalizantes, contudo sabemos que o fim do ciclo básico da PUC SP em 1986 ocorreu por um movimento democrático, comparticipação efetiva dos alunos reivindicando um maior número de disciplinas profissionalizantes nos primeiros anos. Como ficamos deveríamos buscar a formação generalista e humanística primeiro para depois irmos a profissionalização? Como os alunos reagiriam a isso numa IESP.

\section{E como fica o ensino superior privado brasileiro nesse contexto de mudanças?}

A primeira vista parece que não houve inciativas no segmento privado para enfrentar os desafios do século XXI, todavia experiências estão ocorrendo em várias IESPs diferentes, buscando se adequar às mudanças impostas pelos novos tempos.

\footnotetext{
${ }^{29}$ ALMEIDA FILHO, Naomar de e COUTINHO, Denise Nova arquitetura curricular na universidade Brasileira Cienc, Cult. vol.63 no. I Săo Paulo Jan. 2011 disponivel em http://cienciaecultura.bvs.br/scielo.php?pid=S0009$-67252011000100002 \&$ script-sci arttext acesso em 02/04/2012

${ }^{30}$ MARINHO, Rainer idem

${ }^{31}$ ALMEIDA FIL HO, Naomar de e COUTINHO, Denise idem
}

No final dos anos noventa e início do século XXI, a Universidade Anhembi Morumbi implantou duas mudanças significativas uma os cursos sequenciais, conforme MARINHO aponta:

Três anos após a provação da LDB de 1996, inspirada pelo Prof. Darci Ribeiro, este também muito influenciado pelo modelo americano, o Dr. Gabriel Mario Rodrigues resolvei implantar na Universidade uma modalidade de ensino superior prevista na mesma c que havia sido colocada no projeto original da LDB pelo Prof. Darei, era o chamado ensino sequencial, que deferia da graduaçăo tradicional, pois ele tinha um caráter certificador e com duas possibilidades de oferta, uma possibilitando ao aluno buscas sua própria formação, nitidamente inspirada nos comunits colleges americano, e outra mais amarada, que tinha as disciplinas elencadas pela própria IES e com um a duração de dois anos. ${ }^{32}$

Essa proposta depois evolui em outras IES, UNINOVE e a UNIBAN, com a chegada dos chamados cursos de tecnólogos, que vem sendo oferecidos em concomitância aos bacharelados, fazendo na pratica o tecnológico de dois anos seja um ciclo comum seguido de uma formação mais aprofundada num curso de Bacharelado de com mais dois anos.

Na mesma época, a Universidade Anhembi Morumbi também inicia se a tentativa de implantar ao modelo da navegabilidade, que consistia basicamente em o aluno poder se mover entre os vários cursos oferecidos na IES, podendo construir seu próprio curriculo. Desta forma o aluno podia aproveitar as disciplinas cursadas que seriam comuns em diversos cursos e com um pouco mais de tempo tirar um segundo diploma de graduação.

A Revista Ensino superior, recentemente publicado mais dois artigos sobre o tema ${ }^{33}$ que relata a experiência implantada na Universidade Ibirapuera, baseada na interpretação das diretrizes curriculares que permitem a criação de quatro ciclos, conforme foi explicado acima, Assim a IES tem um eixo comum de disciplinas formadoras para toda a instituição, um instrumental para a escola que aglutina os cursos afins, um especifico para o curso e um complementar.

MARINHO $^{34}$ relata, em detalhes um modelo semelhante que foi implantado num centro universitário no interior de São Paulo, apontando dois aspectos importantes da proposta, um acadêmico e outro financeiro,

Assim o projeto de Centro universitário traz uma nova concepção

\begin{abstract}
32 MARINHO, RAINER Um combate a evasão e a ociosidade vagas: uma proposta educacional e financeira A construção de um modelo modular flexível com ingressos bimestrais nâo seriado Case: Um projeto nâo implantado para da Faculdade de Tecnologia Interamerica fruto da pratica historia dos Sequência e da graduação executiva da Universidade Anhembi Morumbi, Disponivel $\mathrm{em} \mathrm{http:/rrconsultoria.wordpress.com/2011/12/31/um-combate-a-cvasao-e-}$ -a-ociosidade-vagas-uma-proposta-educacional-e-financeira-a-construcao-de-um-modelo-modular-flexivel- com-ingressos-bimestrais-nao-seriado-case-um-projeto-nao-implantado-para-d/acesso em 31/03/2012
\end{abstract}

33 REVISTA ENSINO SUPERIOR. Universidade sai na frente e muda grade Instituiç̨o começa ano letivo com reestruturaçăo acadêmica que privilegia a interdisciplinaridade. Cursos serằo agrupados por núcleos de conhecimento. Disponivel em http://revistaensinosuperior.uol.com.br/textos.asp?codigo-11875 e O Desafio é SER ATRAENTE

Alto indice de evasâo nas instituiçōes de ensino superior demonstra desinteresse por parte dos alunos em continuar na graduação. Depois de conquistar novos alunos, o objetivo é mantê-los. Disponivel $\mathrm{cm}$ http://revistacnsinosuperior. uol.com.br/textos.asp?codigo-11874

${ }^{34}$ MARINHO, Rainer, A implantação de curso de graduação na forma modular flexivel num Centro Universitário, disponível em http://rrconsultoria,wordpress. com/2010/06/27/a-implantacao-de-curso-de-graduacao-na-forma-modularflexivel-num-centro-universitario/ acesso em 31/03/2012 
de ensino, não somente pedagógica, mas de gestäo acadêmica, aberta e inovadora que nos coloca diante dos desafios de construir uma universidade para o século XXI, tendo consciência das novas formas de apreender dos nossos alunos agora ancorados no hiperespaço, nas novas midias; é o mundo midiático suportado pelos novos meios tecnológicos de ensino e aprendizagem.

E ai como fica nosso problema de professor que foi aluno na lousa do giz, que agora tem que dar conta de alunos que podem saber mais que eles em alguns assuntos? Ele não mais o catedrático, o dono saber, ele se toma um pedagogo, aquele que anda ao lado do aprendiz para construirem juntos este saber" (...)

No plano financeiro a modularização e flexibilizaçâo possibilita um grande ganho financeiro, pois neste modelo, em funçāo da existência de uma matriz curricular com componentes curriculares comuns(disciplinas) permite que os alunos possam ser agrupados em disciplinas comuns a universidade e a escola e que possam ingressar em turmas já em andamento, fazendo que nāo haja necessidade de abertura de novas turmas, neste sentido com múltiplas entradas no ano, podemos aumentar o número de alunos em aumentar o numero de salas e de custos com professores.

Finalizando, o ensino superior privado não está à margem das mudanças que estão ocorrendo no mundo sobre $o$ ensino superior, inclusive ele tem mais agilidade que $o$ sistema federal para fazer essas mudanças e por ser mais ágil para responder a novas demandas, tendo em vista que o processo decisório não tem tantas limitações como as públicas, e que no caso das universidades privadas possui uma relativa autonomia decisória, muitas vezes cerceada pelo processos regulatórios do MEC. Todavia, talvez o maior empecilho para que essas mudanças ocorram é a própria sociedade tendo em vista que dos nossos alunos, muitos não compreendem a inovação proposta , ficando ainda presos a antigos paradigmas educacionais. E como temos até certo ponto que atender à demanda de nosso público alvo: os alunos, essas mudanças têm de ocorrer em um ritmo adequado.

Num contexto do sistema particular de ensino superior em que há uma "comoditacão" da oferta de cursos, no nosso caso dos produtos educacionais, bem como de infraestrutura, a busca de uma diferenciação nas ofertas de curso e de suas matrizes passa ser um objetivo para se diferenciar de nossas concorrentes ou simplesmente para se destacar no mercado extremamente competitivo.

Os dados do Censo do Ensino Superior $2010^{35}$ demonstra a extrema concentração de alunos matriculados em poucos cursos e poucas IESPs, no qual as 20 maiores IESPs detêm $34,6 \%$ do total das matriculas no presencial e que os cinco principais cursos têm $40 \%$ do total de matrículas, num universo de mais de 3000 nomenclaturas de cursos diferentes, o que coloca $o$ segmento privado numa eterna busca de diferenciais para se destacar no mercado.

Todavia as pequenas IESPs que são ainda a maioria, num total de mais de $60 \%$ com menos de 1000 alunos $^{36}$, por nâo possuírem autonomia universitária, vivendo portando mais ainda sobre a tutela reguladora do $\mathrm{MEC}$, que tolhe boa parte da possibilidade de inovaçào, seja por medo infundado ("o pessoal de Brasilia não deixa") ou por restrições reais, acabam se

\footnotetext{
${ }^{35}$ CAPELATO, R. Cenário do Ensino Superior no Brasil. Palestra proferida num encontro na FEI CAPELATO. R. Cenário do Ensino Superior no Brasil. Palestra proferida num encontro na FEI do campus Säo Paulo no programa de pós-graduação de Administraçăo em 23 de novembro de 2011

${ }^{36}$ Resumo técnico Censo do Ensino Superior 20101-MEC
}

encontrando numa situação de não terem coragem de inovar, o que certamente poderá ser sua sentença de morte.

O segmento privado tem restrições legais, impostas pelo MEC, como já dissemos acima, mas também tem restrições que o próprio mercado impõe, seja por comodismos e inercia por dos subscts, seja pela vigểncia de um paradigma educacional que não se consegue romper.

Veja o caso dos cursos Tecnológicos, que nos seus primeiros 5 anos patinaram em número de matrículas, seja por uma não compreensão do que eles eram realmente seja pela concorrência de preços baixos dos cursos já tradicionais de bacharelado e licenciaturas, prática iniciada naquele momento histórico. Tivemos que esperar ascensão da nova classe $\mathrm{C}$, para que esses cursos se tornassem uma opção real de cursos de nivel superior, em função de sua duração e do aspecto profissionalizante tão admirado por esse grupo social, o que faz em 10 anos de existência, que ele passasse a responder por $14 \%$ do total de matriculas ${ }^{37}$.

Em relação à proposta de inovação, temos a tentativa da UMC, nos anos noventa de implantar o ciclo básico de formação humanista capitaneada pelo Prof. Lobo tendo enorme resistência por parte da comunidade acadêmica e acabou sendo abandonado.

Mas recentemente em 2007, a Universidade Anhembi implantou um modelo piloto chamado de Graduação Executiva, elaborado pelo Prof. Paulo Vadas, que colocou em prática um modelo de inspiração norte americana com uma matriz flexivel modular, que tinha no ciclo básico 10 disciplinas de caráter formador humanístico profissional, com a diferença que não havia ciclos a serem seguidos de forma pré-estabelecida.

Nesse panorama as inovaçóes trazidas pela Universidade Nova, seja como uma superação do Protocolo de Bolonha ou uma adequação, permitir que se busquem novas formas de ofertas de ensino superior, trazendo ganhos para os alunos. O importante nesse processo está sendo o aparecimento de novas propostas para o modelo existente, permitindo uma reflexão sobre quais são os novos caminhos que o ensino superior deverá trilhar nos próximos anos, seja para garantir sua real expansāo e o seu aumento de qualidade.

A volta do Ciclo Básico ou como a Universidade Nova chama Bacharelado Interdisciplinar, agora com um significado ampliado é um bom caminho para se buscar o nivelamento acadêmico dos estudantes oriundos de uma rede pública que ainda peca pela qualidade de ensino, e que tem se tornado a maioria dos alunos na IESPs. Isso traria ganhos acadêmicos e também financeiros para IESPs, tendo em vista que o aluno, caso não se identificasse com o curso durante o primeiro ano, pudesse se transferir para outro sem perder o seu tempo nem dinheiro, e para IESPs ć uma forma de reduzir aversão do primeiro ano, que é o período crítico de perda de alunos ${ }^{38}$.

Um outro aspectos é o incentivo: a educação continuada, coma visão de que a pós-graduação é um continuação direta da formação de graduação, o que contudo no caso das IESP's deve ser visto como uma oferta na modalidade de lato sensu, em dos altos custo de manutenção de programas de stricto sensu.

Nesse sentido, é possivel se aprender com essas inciativas vendo nos seus erros e acertos as novas possibilidades para as IESPs que querem fazer a diferença.

\footnotetext{
$37^{3}$ jdem

${ }^{38}$ MARINHO, Rainer. A evasấo no cnsino superior- Como podemos tentar evita-la .Disponivel em hitp://abmeseduca.com/ $\mathrm{p}=3411$, acesso $\mathrm{em} 31 / 03 / 2012$
} 


\section{Referências}

CROCHÉ, Sarah et CHARLIER Jean-Émile. Le processus de Bologne et ses effets, numéro de "Education et sociétés", 2009/2. Disponivel $\mathrm{em}$ http://www.sauvonsluniversite.com/spip.php?article3621 acesso em $02 / 045 / 2012$

NEVES, Clarissa Eckert Baeta. Reforma e desafios da educação superior: o processo de bolonha dez anos depois. Disponível em http://revistappgsa.ifes.ufri.br/pdfs/anolv1_artigo clarissa-neves.pdf. Acesso em 30/03/2012

LIMA Licinio C. 1; AZEVEDOII, Mário Luiz Neves de; CATANIII, Afrânio Mendes. O processo de Bolonha, a avaliação da educação superior e algumas considerações sobre a Universidade Nova, Avaliaçăo: Revista da Avaliação da Educação Superior (Campinas) Avaliaçăo (Campinas) vol.13 n.1 Sorocaba Mar. 2008. Disponivel em http:// dx.doi.org/10.1590/S1414-40772008000100002, acesso em 30/02/12 CHIANG, Iris Kuang-Hsu: Deux cents ans aprés la réforme d' Humboldt: Bologne Où va l'enseignement supérieur européen, Le processus de Bologne et ses effets", numéro de "Education et sociétés", 2009/2vendredi 26 mars 2010. Disponivel em hitp://www.sauvonsluniversite. com/spip.php?article3621, acesso em 1/04/2012

FERREIRA, Suely. Reforma da educação superior no brasill e na Europa: em debate novos: Papéis sociais para as universidades. Disponivel em http://www.anped.org.br/33encontro/app/webroot/files/file/ Trabalhos $\% 20 \mathrm{em} \% 20 \mathrm{PDF} / \mathrm{GT} 11$-6003--Int.pdf, acesso em 1/04/2012 MARTINS, Leila Chalub e NASCIMENTO, Elimar Pinhero do. O Processo de Bolonha no Ensino Superior da América, Latina: o caso brasileiro IN PENA-VEGA ,Alfredo (Coord.) O Processo de Bolonha no Ensino Superior da América Latina, OBSERVATÓRIO INTERNACIONAL DE REFORMAS DA UNIVERSIDADE Disponivel em http://www.gulbenkian.pt/media/files/agenda/eventos 2009/Futuro $\% 20$ de $\% 20$ Bolonha/TRADUCTION PROCESSO BOLONHA FINAL-4. pdf acesso em 30/03/12

Le processus de Bologne et ses effets, numéro de "Education et sociétés", 2009/2vendredi 26 mars 2010. Disponivel em http://www. sauvonsluniversite.com/spip.php?article3621, acesso em 1/04/2012

MARINHO, Rainer, A implantação de curso de graduação na forma modular flexivel num Centro Universitário. Disponivel em http:// rrconsultoria.wordpress.com/2010/06/27/a-implantacao-de-cursode-graduacao-na-forma-modular-flexivel-num-centro-universitario/ acesso em 31/03/2012

REVISTA ENSINO SUPERIOR, Curriculos em Mudança. Disponivel em http: $/ /$ revistaensinosuperior.uol.com.br/textos.asp?codigo $=12393$ Opçâo pela mudança: Universidades Federais discutem o projeto Universidade Nova, que pode mudar completamente o perfil curricular do ensino superior no Brasil. Disponivel httpem://revistaensinosuperior. uol.com.br/textos.asp?codigo=11880, acesso em 31/03/2012

FERREIRA, Suely. Reforma da educação superior no brasil e na Europa: em debate novos: Papéis sociais para as universidades. Disponivel em http://www.anped.org.br/33encontro/app/webroot/files/file/ Trabalhos $\% 20 \mathrm{em} \% 20 \mathrm{PDF} / \mathrm{GT} 11-6003$--Int,pdf, acesso em 1/04/2012 MELLO, Alex Fiúza da; ALMEIDA FILHO, Naomar de: JANINE RIBEIRO, Renato. POR UMA UNIVERSIDADE SOCIALMENTE RELEVANTE. Disponivel em http://portal.mec.gov.br/dmdocuments/ cne_alexfiuza.pdf acesso em 31/03/2012.

UFBA, Universidade Nova: Plano de Expansão e Reestruturação da Arquitetura Curricular na Universidade Federal da Bahia. Documento Preliminar. Campinas, Mimeo

UFBA, Universidade Nova: Plano de Expansão e Reestruturação da Arquitetura Curricular na Universidade Federal da Bahia. Documento Preliminar. Campinas, Mimeo, 2007, p. 9-10

Apud MARTINS, Leila Chalub e NASCIMENTO, Elimar Pinheiro do. O Processo de Bolonha no Ensino Superior da América, Latina: o caso brasileiro IN PENA-VEGA, Alfredo (Coord.) O Processo de
Bolonha no Ensino Superior da América Latina, OBSERVATÓRIO INTERNACIONAL DE REFORMAS DA UNIVERSIDADE. Disponivel em http://www.gulbenkian.pt/media/files/agenda/eventos 2009/ Futuro $\% 20 \mathrm{de} \% 20$ Bolonha/TRADUCTION_PROCESSO BOLONHA_FINAL-4.pdf acesso em 30/03/12

ALMEIDA FILHO, Naomar de e COUTINHO, Denise. Nova arquitetura curricular na universidade Brasileira. Cienc. Cult. vol.63 $\mathrm{n}^{\circ} .1$ São Paulo Jan. 2011. Disponivel em http://cienciaecultura.bvs. br/scielo.php?pid=\$0009-67252011000100002\&script $=$ sci arttext acesso em 02/04/2012

MARINHO, RAINER. Um combate a evasão e a ociosidade vagas: uma proposta educacional e financeira A construção de um modelo modular flexivel com ingressos bimestrais não seriado Case: Um projeto nâo implantado para da Faculdade de Tecnologia Interamerica fruto da pratica historía dos Sequéncia e da graduação executiva da Universidade Anhembi Morumbi. Disponivel em http://rrconsultoria. wordpress.com/2011/12/31/um-combate-a-evasao-e-a-ociosidadevagas-uma-proposta-educacional-e-financeira-a-construcao-de-ummodelo-modular-flexivel-com-ingressos-bimestrais-nao-seriado-caseum-projeto-nao-implantado-para-d/acesso em 31/03/2012

REVISTA ENSINO SUPERIOR. Universidade sai na frente e muda grade. Instituiçăo começa ano letivo com reestruturação acadêmica que privilegia a interdisciplinaridade. Cursos serão agrupados por núcleos de conhecimento. Disponivel em http://revistaensinosuperior: uol.com.br/textos.asp?codigo $=11875$ e O Desafio é SER ATRAENTE MARINHO, Rainer. $A$ implantação de curso de graduação na forma modular flexivel mum Centro Universitário. Disponivel em http:// rrconsultoria,wordpress.com/2010/06/27/a-implantacao-de-cursode-graduacao-na-forma-modular-flexivel-num-centro-universitario/ acesso em 31/03/2012

CAPELATO, R. Cenário do Ensino Superior no Brasil. Palestra proferida mum encontro na FEI do campus Sâo Paulo no programa de pós-graduação de Administração em 23 de novembro de 2011

Resumo técnico Censo do Ensino Superior 2011-MEC 